\title{
World Policy Issues
}

Change in Technology and its Impact on Delocalisation: An Illustration Based on the European Financial Industry

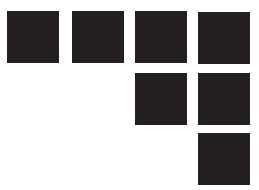

Today's and tomorrow's worlds are radically different from yesterday's. Selfevident, yet our thought processes often remain anchored in outdated mindsets. The weight of our success and experience can create "an excess in reasoning that drains our energy" (Erik Orsenna, Voyage aux Pays du Cotton). Globalization is an evolutionary stage in our societies, an evolutionary process that is ancient and at the root of our prosperity. The financial industry does not escape this process and the technological evolution is an accelerator... as was already the case in the Middle Ages with the invention of letters of credit between Flemish and Italian markets. Adam Smith identified in international specialization a source of wealth for each country involved. With two billion workers from emerging countries entering into and radically reinforcing world labor pools, and hence potential world consumption, why would our era be any different? It is clear that as in the past, but this time with a suddenness and extraordinary amplitude, the progress in technologies is changing the ensemble of value scales, distances, time and production processes. From 1930 to 1990 the cost of maritime transportation has been divided by two, air transportation by six, that of telecommunications by 80 and, lastly, the cost of IT structures has been divided by 1000 since 1960. Resources, markets, and companies are thus global..., but there remains an invariable reality: countries remain in place, they still remain platforms of wealth serving their citizens and businesses that choose their territory and eco-system. If globalization is an evident reality, it can be an opportunity only if each of its components is taken into consideration in a real strategic perspective with neither concession nor confusion.

In this context, the nature of the chain reactions that lead to an inevitable process of delocalisation must first be well defined. Then the limits stemming from a technological complexity must be understood and lastly, the most appropriate delocalisations for our financial centers must be explored.

\section{The finance industry concentrates around a competitive pole} and a critical mass.

Although it has taken time, today's world of finance emerges from an aristocratic ghetto tied to servicing of money to a veritable value-added industry organized around market, post-market, and credit centers, distribution circuits, and hands-on consulting for large and small clients. These financial activity centers can be now be envisioned as "bank factories" comparable in their processes to real manufacturing factories. It is because of this established industrial dimension that the question of delocalisation ("Relocalisation, or delocalisation, a term derived from the French, refers to the migration of certain jobs and production to other parts of the world, mostly developing countries." - Frans A. van der Zee), can be posited in terms of job and value creation. In macro-economic terms the financial industry in France represents between 700,000 and one million jobs if 
one includes service providers to financial institutions. Within a mere ten years, replenishing a full third of these jobs will be necessary. This time frame clearly forces each institution to analyze the fundamental questions and evaluate its best alternatives. This human resource issue will need to answer to a series of complex criteria tied to the financial industry's policies, to the creation of value in a financial center, to a distribution model for services and consulting. In considering this last point, everyone will remember at the time of the internet bubble the discourse as to the "click vs. mortar" battle; the mortar being summarily dismantled (virtual banks vs. physical branch bank networks). Reality is far more complicated and the real world of contact between clients and counselors has happily a long life before it, where technology helps maintain these contacts on the essential level.

In order to illustrate this chain of reactions at the heart of the delocalisations, let's observe what has taken place in bank branches since outsourcing is not an international phenomenon to start with but a series of small, local reorganizations that factors certain tasks. For a long time, a branch was a small entity, autonomous and invested with all the necessary operational means. The world was stable. Branches had their own telephone systems and back-offices. When these functions were moved to a distance and regrouped, first by clusters, then regions, eventually nationally and internationally, a real revolution took place. For some it was an engineer's utopia, but today it is a reality that has come about in less than ten years.

A little further back, a similar phenomenon also took place in the marketing and sale of trading room services. Senior bankers were now also in charge of selling multiple financial products to domestic or foreign institutions. Technology had allowed for the creation of trading rooms as real "factories" of dematerialization, specialized by products and bringing traders face to face with clients. These trading rooms started an upward industrial spiral answering to two major criteria: critical mass in technological know-how, and access to a deep pool of skills and proficiency.

Post-Market activities offer one last example. Approximately 30 years ago, the "bank factories" for custody services left Paris for the provinces.... at the same time these "factories" dedicated to providing custody services to their own bank's clients discovered they could develop a standalone business line by concentrating and providing contractual services to other domestic and foreign banks. A similar realization occurred in the payment centers, another "bank factory." Soon a new business environment took hold, that of outsourcing domestically and outsourcing across borders, delocalizing. At this point, a significant part of the delocalisation was done for IT reasons. But what is important to note is that the very nature of business had changed in becoming much more industrial. The cost analysis switched from variable to fixed; and work lines switched from that of standardized production to that of treating exceptions and dysfunctions. All of this thoroughly enriched the quality of the services yet also heightened and amplified the potential risks.

At first, these jobs were profoundly restructured and concentrated at a national level. Today's latest evolutionary wave is the result of European harmonization transforming the European "territory" into a space as efficient as countries' individual domestic areas. This is the objective of the European guideline on payments (SEPA-Single European Payment Area), the guideline on Post-Markets, as well as the European Central Bank's initiative to create a single platform for the delivery and payment of securities (Target 2 Securities) as a complement to the platform dedicated to inter-bank payments (Target 2 delivery in 
November 2007). To all these initiatives one needs to add the recent bank consolidations within Europe that have profited from the conditions of European harmonization in terms of infrastructures, legal structures, regulations, and operational practices by taking the logic of critical mass from the national level to the European level. The new "factories" in the years to come will target serving the entire European clientele. Even if this is good news for the European customer (corporations, institutions, and individuals), it doesn't come without raising questions on the conditions for implementation and what will be the status of winners and losers.

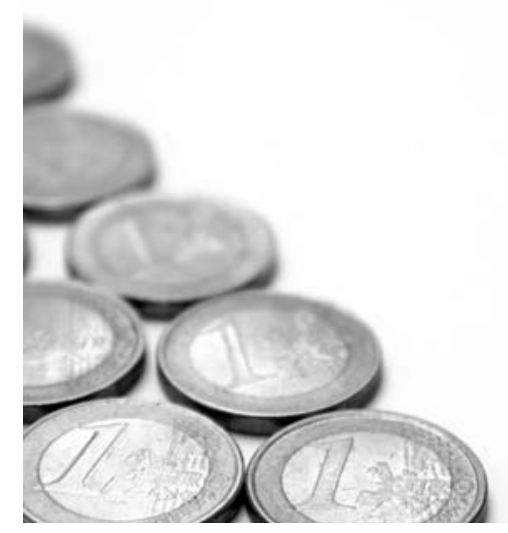

To conclude, the third strata of potential consolidation is at a global scale. Two axes justify this: on the one hand, the global nature of business lines. A global corporation's choice of production sites is determined by the localisation of its final clients, by local prices and by its ability to centralize production factors in order to optimize the size and cost of its resources. On the other hand, for a local or regional business line, the question arises as how best to serve a local clientele from delocalized production sites in order to better leverage the best production costs in order to meet the competitive challenge of global players. Well-known examples are customer service call centers, IT centers and certain administrative centers.
Delocalisation contributes to the efficiency of production systems and to employee's purchase power in emerging economies. It creates a virtuous economic spiral. It is clearly at work in the competitiveness of European companies. This opportunity, however, is neither without limits nor constraints. It will structure over time the terms of the competition, and in the short run it presents real strategic risks.

\section{The limits of Delocalisation}

When it comes to delocalisation, financial service centers have several limitations such as the level of financial sophistication, the risks, and the competition with local resources in a host country. As we have seen, the evolution of financial "factories" has dematerialized and automated the production process leaving personnel with only value-added tasks. Workers have transitioned from simply processing instructions into transaction monitors or circuit-integration engineers, the circuits themselves becoming more and more complex. Today's workers face increasingly sophisticated service requests demanding increasingly rapid reaction times. Beyond technology, the interactivity between different layers of specializations, and different frontlines, implies extremely interoperable organizations. It is true that in the sophisticated domain of software development, the establishment of procedures and the development of new methodologies based on computerized workflows, has allowed the uncoupling of relations that formerly required physical proximity. Nevertheless, the increase in the technological intensity of processes can become a barrier to the delocalisation of certain functions. One must note that in this area of skills, France belongs to those countries most advanced in the automation of these processes, and this explains its lesser degree of delocalisation.

Risk is also specific to the banking industry. With a strong concentration of 
actors in transaction banking and in trading, understanding the dimension of systemic risk has become more clearly measured in the ratio calculations of capital and is the outcome of Basel II standards. These new ratios explicitly take into account operational risk. These risks, above and beyond the quality of the "factories" that can be built cross borders, need to take into account the security conditions of energy and telecommunication structures. Do these have strong enough back-up systems based on alternate circuits or on the capacity to mirror data through the use of fiberoptics as is the case in western countries? To that is added climatic risk in countries with extreme conditions little known in more temperate climes.

The last significant limit to delocalisation is the competition between the development of the local markets of the host countries and the pressure from external markets for the same resources. The impact is immediate on salaries even if the gap remains significant (approximately 1 to 4). But the real challenge for these countries is the penury of qualified personnel and the arbitrage between different production centers as they accompany either the local or the external development. Delocalized activities are a strong accelerator for the development that sparks this upward spiral and the establishment of a middle class that quickly expects services quasiequivalent with those in Europe. In India, 300 million people have seen their annual revenue increase in 20 years from $\$ 4,500$ to $\$ 23,000$. In Algeria, closer to France, the banking system is undergoing profound reforms leading to payments systems being established that meet western standards and that imply the same level of back-offices and project management resources that might have been allocated to delocalized centers. In the region of Suzhou near Shanghai, the authorities are worried about the possible perennial nature of foreign companies in their "territory" and anxious that they develop without bothering the local Chinese companies. Despite impressive efforts in education, it is evident that the pool of qualified resources will be quickly stretched. The elasticity of a new work force of 2 billion is not without limits in terms of economic and opportunity costs.

\section{A serious challenge to meet}

The rules of the game are clear and the consequences imaginable. A strong delocalisation of trading activities to London has already been seen. An important number of French researchers, particularly in mathematical finance, have moved to the US and the UK. A strong French Diaspora exists around the world in the areas of mathematical modeling of trading instruments (derivatives) and of risk management. The Post-Market will likewise be subjected to structural change. The competition between territories is not new; it nevertheless implies that this competition must be managed in as professional and determined a manner as competition between businesses demands. A territory, and specifically, a financial center, is a service platform where the competitive factors are talent, liquidity, regulation, legal structure, and market infrastructures... However market forces alone will not organize these factors into the best competitive offer. That can only be the result of a real strategic plan based on an industrial policy, regardless of the name given to this approach, just as is the case for corporate businesses.

The Paris Financial Center's success will be conditioned by Europe's success. Even for the international financial centers like London and New York it would be presumptuous to think that their individual success could be independent from their "territorial" base-camps. For the European centers, this implies that their force will come from a complementary network of European financial centers.

This policy can have several objectives. First, the Diaspora of French 
"Quants" is not a weakness but a force in the French system. For that, their connection with their home base must be strengthened. A second objective is to put into place conditions attracting the relocation of trading or fund management activities in reaction to new market opportunities. London did this a few years ago, when it attracted hedge funds along with the derivatives market that in a very short time together drove the growth of the London financial center. This strategic and economic pull-effect is key. When one looks at studies of New York one observes that financial jobs represent $2.2 \%$ of the State's population but $12.5 \%$ of wages, and $13.8 \%$ of tax revenues. Beyond the strategic consequences of finance on the control of decision centers in this eco-system, the leverage of financial wealth is important. In New York, one financial job justifies two non-financial jobs. One can even say that these jobs (2.2\%) justify $17 \%$ of private sector jobs!

A third objective is to maintain in France the significant advantage it holds in the Post-Market job sectors. Is this utopia? Insofar as the "battlefront" is structurally concerned, the possibility exists. Major constraints such as French social and tax costs, are currently being addressed by the French political authorities. However, this battle takes place on several, insidious fronts. Take for example the global convergence of law. The law regarding title to securities is certainly a sign of a system's robustness and it determines the quality of the relations between shareholders and issuers, in particular during general assemblies, the cornerstone of western tradition. It is also an essential competitive element. The example of the debate on the rules for conflicts of law in the area of custody is symptomatic of the problems. A technical debate at the juncture of law and post-market operations has bogged down in multiple layers of profound incomprehension. The heaviness of the underlying polemics is in reality due to the real strategic consequences that it hides. In these debates, the terms of delocalisation must also be treated responsibly without naiveté.

At this stage, without entering into details, success will depend on the extent of the "top-down" process. In London, the City did this 20 years ago at the time of their "big-bang". So has the US, following the recent reports on Hal Scot and Bloomberg on the competitiveness of American regulations following the Sarban-Oxley law. As far as France is concerned, it must strongly mobilize itself in terms of research in the areas of finance, law, regulation and quantitative finance. It must invest in market infrastructures and supporting technologies for related skills. The challenge of delocalisation can be for the good if it allows France to move up the value chain and bring with it the totality of necessary jobs.

This challenge goes beyond simple economic patriotism but highlights the responsibility of what is termed the general interest. It requires a concerted mobilization of involved industries and public powers. The roundtable that the President of France just organized on the financial industry confirms this. The same goes for the projects that concern university autonomy necessary in order to participate in the Lisbon Agreement, a European objective to take world leadership in the knowledge industry. But if the "top-down" confirms itself, the centrifugal forces of "bottom-up" are always present to balkanize the energies. It is at exactly this level that leadership must reveal itself in the industry to sublimate categorical reflexes. The strengths of the Paris Financial Center are serious strengths. France's challenge is to manage delocalisation and to turn finance into a motor for the creation of wealth in Europe, in Paris and for its local and international clients. 